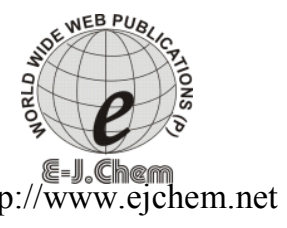

\title{
Indirect Electrochemical Analysis of Crocin in Phytochemical Sample
}

\author{
RIYAZ AHMAD DAR ${ }^{\mathrm{a}}$, PRADEEP KUMAR BRAHAMAN ${ }^{\mathrm{a}}$, \\ SWEETY TIWARI ${ }^{\mathrm{a}}$ and KRISHNA SADASHIV PITRE ${ }^{\mathrm{a}}$
}

Chemical Technology Laboratory, Department of Chemistry Dr.Hari Singh Gour University, Sagar-470003, Madhya Pradesh, India

riyazabid.2008@rediffmail.com

Received 2 July 2011; Accepted 4 October 2011

\begin{abstract}
A new electroanalytical method has been developed for the quantitative determination of crocin in a sample of stigmas of saffron (Crocus sativus L.). Crocin is polarographically inactive. However, cysteine in $0.02 \mathrm{M} \mathrm{NaCl}$, $\mathrm{pH}=5.2 \pm 0.01$ produces a well defined wave/peak with $\mathrm{E}_{1 / 2} / \mathrm{Ep}=-0.47 /-0.45 \mathrm{~V}$ vs. $\mathrm{Ag} / \mathrm{AgCl}$. On recording polarograms of a set of solution containing a fixed concentration of cysteine and varying concentrations of crocin under aforesaid experimental conditions a gradual decrease in peak height/diffusion current and a negative shift in peak potential was observed. Thus, indicating cysteine-crocin interaction. Amperometric titration indicated crocin to cysteine ratio of 1:2. The above amperometric titration procedure has been used to determine the concentration of crocin in a sample of saffron. Crystallization process was carried out for the extraction of crocin from dried powder of saffron stigmas. The crystallized crocin was identified by UV-Visible spectrophotometry(at $255 \mathrm{~nm}$ and $442 \mathrm{~nm}$ ) and the quantitative analysis by the developed amperometric method. The concentration of crocin in saffron was found to be $2.13 \%$ and purity of isolated crocin $96.81 \%$. The percent recovery varied from $98.56-100.31 \%$ and $\operatorname{RSD}(n=5)$ of $2.17 \%$. The validation of the proposed procedure for the quantitative assay of crocin was examined via an evaluation of the repeatability, recovery, selectivity and relative standard deviation.
\end{abstract}

Keywords: Crocus sativus, Crocin, [Cro-(cys) $\left.{ }_{2}\right]$ adduct, Amperometry.

\section{Introduction}

Saffron is a food spice obtained from the flower, stigmas of Crocus sativus L.a member of the iridaceae family. It plays an important role in the culinary culture of different regions of the world where it is used as a food. In view of its wide range of medical uses, saffron has undergone extensive phytochemical and biochemical screening and a variety of biologically active ingredients have been isolated from it. Characteristic components of saffron are crocin - responsible for the colour, picrocrocin - responsible for the bitter taste and safranal - responsible for odour and aroma. The amount of these main compounds present in saffron 
decides its quality. Saffron is non toxic in animal studies $\left(\mathrm{LD}_{50}-20.7 \mathrm{~g} / \mathrm{kg}\right)$, non cytotoxic in vitro studies $\left(\mathrm{LD}_{50}-200 \mathrm{mg} / \mathrm{kg}\right)$ of body weight of mice ${ }^{1,2}$. The literature records a large amount of data on the effect of saffron on coronary artery diseases, learning behavior, ocular blood flow and retinal function, blood pressure and for its possible use as contraceptive, anti-inflammatory, anti-atherosclerosis, antioxidant, antigentoxic, and cytotoxic agent ${ }^{2-6}$. Saffron also shows a positive effect on male erectile dysfunction (ED). Saffron is considered to be rejuvenative and nourishes the brain cells by supporting the nervous system and enhances co-ordination and memory. Oral administration of saffron may be useful as treatment for neurodegenerative disorders and related memory impairment. It is a drug that promotes intelligence, memory, freedom from disease, longevity, strength of the senses and great increase in the strength of the digestion. Whether these claims are valid is a subject of great interest and should be probed scientifically.

The main ingredient of saffron is crocin. It is a natural carotenoid and is also found in Gardenia Jasmenoides. It is the diester formed from gentiobiose and the dicarboxylic acid crocetin. It has a deep red color and forms crystals with a melting point of $186{ }^{\circ} \mathrm{C}$. When dissolved in water, it forms an orange solution. It has also been shown to have an anticarcinogenic action $^{6-9}$. Crocin $(200 \mathrm{mg} / \mathrm{kg}, \mathrm{i}, \mathrm{p}$. $)$ did not show anticonvulsant activity ${ }^{10}$. It means crocin must be a good anti depressant. Chemically it is $(\beta, \beta$ 'digentiobiosyl 8 , 8 'diapocarotene 8, 8'oate or crocetin digentiobioside ester Figure 1).

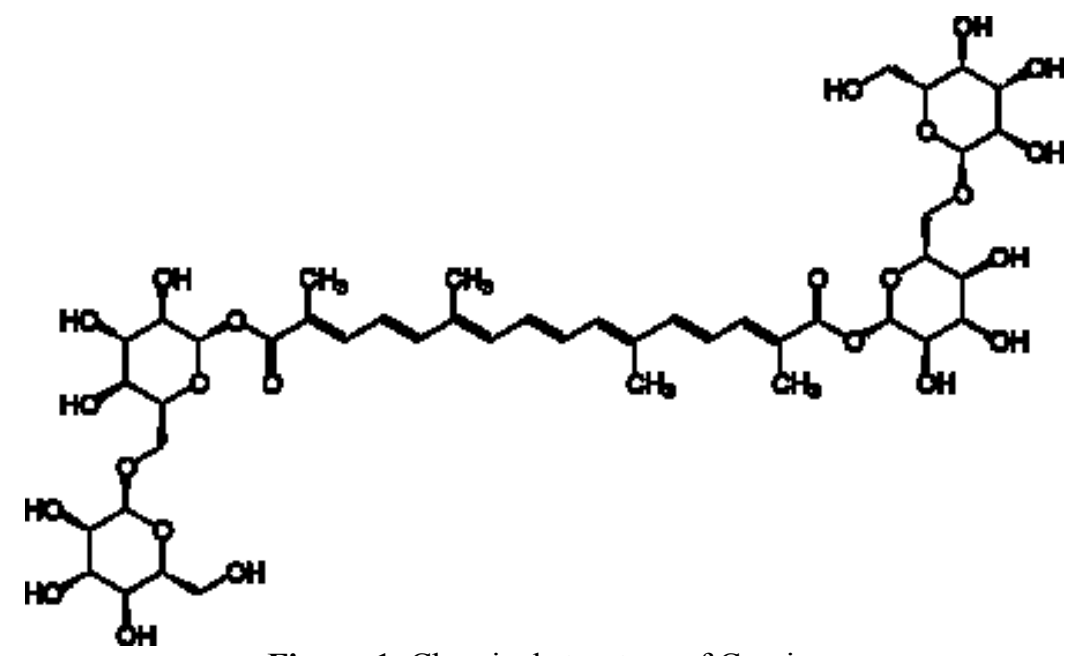

Figure 1. Chemical structure of Crocin.

Crocin has been determined earlier in Crocus sativus ${ }^{11,12}$ and Gardenia Jasmenoides Ellis, ${ }^{4,13}$ using some analytical techniques. Though, the use of polarographic and voltammetric methods have been widely done for the analysis of organic compounds in samples of natural origin $^{14,15}$ but, crocin being polarographically inactive could not be analyzed using this electrochemical method. The authors have therefore developed a new electrochemical method for the determination of crocin in saffron samples. Crocin interacts with a polarographically active compound cysteine in aqueous acidic medium in the ratio of 1:2. The method will also be useful for the quality control assay of the drug in pharmaceutical formulation and in fluids like serum, urine and blood. The authors have also attempted modification of crocin with cysteine. The work has been supplemented by FTIR spectral studies. 


\section{Experimental}

Stigmata of saffron (Crocus sativus L.) were acquired from a saffron grower in Pampur village of Pulwama, Kashmir and stored at low temperature $\left(4^{0} \mathrm{C}\right)$ until further use.

\section{Chemicals and Reagents}

Sigma Chemical Co. (USA) grade crocin and cysteine hydrochloride were used for the present work. Other chemicals used in the present work were either of Anala R or Himedia Laboratories Pvt.Ltd. Mumbai grade. Standard solution each of crocin and cysteine hydrochloride was prepared by dissolving them in requisite amount of distilled water.

\section{Apparatus}

The DPP and DCP studies were carried out in Exploratory mode and peak analysis in Determination mode on a software version 3.1 $\Omega$ Metrohm 797 VA Computrace (ion analyzer). The polarographic cell consisted of a three electrode assembly and a stirrer having a dropping mercury electrode (DME) as a working electrode, a platinum wire as auxiliary electrode and $\mathrm{Aa}^{+} / \mathrm{AgCl}$ electrode as reference electrode. The nitrogen gas was purged for 5 minutes in each experiment. A systronics digital $\mu \mathrm{pH}$ meter model-361 was used for $\mathrm{pH}$ measurements.

The amperometric titrating apparatus consisted of a DME as working electrode, a calomel electrode as reference electrode and a $\mu \mathrm{A}$ galvanometer (polyflex) of sensitivity $10^{-6}$ Amp/div. Attached to an AJCO Vernier Potentiometer. Characteristics of the DME had $\mathrm{m}^{2 / 3} \mathrm{t}^{1 / 6}=2.5 \mathrm{mg}^{2 / 3} \mathrm{sec}^{-1 / 2}$ at $60 \mathrm{~cm}$ effective height of mercury column. The UV-Visible spectrophotometric measurements were carried out using an Elico SL164 Double beam UVVIS Spectrophotometer in the range of 200-600 nm. FTIR spectral analysis was carried out on a Shimadzu Corporation FTIR-spectrometer, model-8400S.

\section{Experimental protocol}

\section{Extraction of Crocin from Saffron Stigmas}

Crystallization process was carried out in two steps at different temperatures for the extraction of crocin from dried powder of saffron stigmas ${ }^{16}$. Among the solvents water was the most convenient for crocin extraction from saffron stigmas.Saffron stigmas powders $(10 \mathrm{~g})$ were suspended in $25 \mathrm{~mL}$ triply distilled water at $0^{\circ} \mathrm{C}$ and shaked by vortex for $2 \mathrm{~min}$. After centrifugation at $4000 \mathrm{rpm}$ for $10 \mathrm{~min}$ the supernatant was separated. Twenty five millilitre of water was added to sediment and extraction was repeated again. This step was repeated 6 other times. The total volume of solvent consumption for $10 \mathrm{~g}$ saffron stigmas in extraction process was $200 \mathrm{~mL}$ $(8 \times 25 \mathrm{~mL})$. The resulting solution was kept in a thick walled glass container at $-5^{\circ} \mathrm{C}$ for 24 days in darkness. The container was sealed in this period. The obtained crystals were separated from solution and washed with acetone to remove remaining water. The yielded amount of crystals was $0.31 \mathrm{~g}$. In the next step; the obtained crystals were dissolved in $120 \mathrm{~mL}$ ethanol $80 \%$ and kept at $5^{\circ} \mathrm{C}$ in darkness for 20 extra days for re-crystallization. The final amount of yielded crystals was $0.223 \mathrm{~g}$ with melting point of $146^{\circ} \mathrm{C}$. The identification of extracted crocin was done by comparing its UV-Visible spectrum with the Fluka crocin (Sigma-Aldrich).

\section{Study on the Crocin-Cysteine Interaction}

A known concentration of cysteine hydrochloride $\left(1 \mathrm{~mL} 10^{-3} \mathrm{M}\right)$ was taken in a polarographic cell containing $5 \mathrm{~mL}$ of $0.1 \mathrm{M} \mathrm{NaCl}$ as supporting electrolyte. The volume of analyte was made up to $25 \mathrm{~mL}$ with distilled water. The $\mathrm{pH}$ was adjusted to $5.2 \pm 0.01$ with dilute solutions of $\mathrm{NaOH} / \mathrm{HCl}$. The solution was deaerated by purging nitrogen gas for five 
minutes and the polargram was recorded. Cysteine produced a well defined polarographic response in sodium chloride $(0.02 \mathrm{M})$ solution with $\mathrm{E}_{1 / 2} / \mathrm{E}_{\mathrm{P}}=-0.47 \mathrm{~V} /-0.45 \mathrm{v}$ in DCP and DPP mode respectively (Figure 2 (A, B).
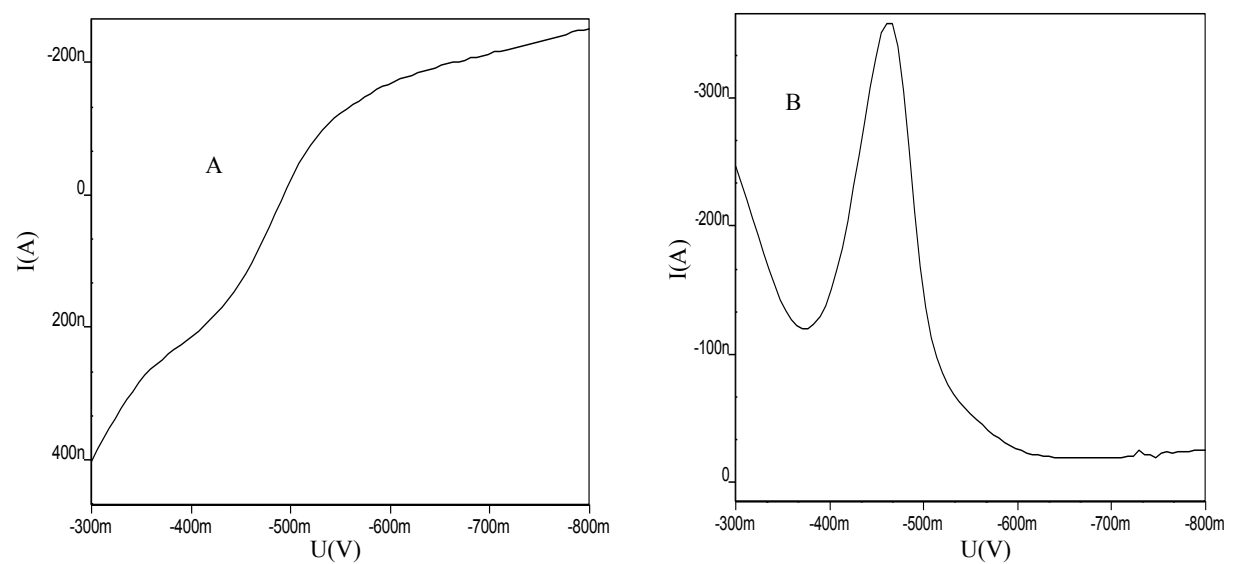

Figure 2. (A).Direct current Polarogram of $2 \mu \mathrm{M}$ cysteine in $0.02 \mathrm{M} \mathrm{NaCl}, \mathrm{pH} 5.2 \pm 0.01$, scan rate $20 \mathrm{mV} / \mathrm{s}$. (B). Differential Pulse Polarogram of $2 \mu \mathrm{M}$ cysteine in $0.02 \mathrm{M} \mathrm{NaCl}, \mathrm{pH}$ $5.2 \pm 0.01$, scan rate $20 \mathrm{mV} / \mathrm{s}$, pulse amplitude $50 \mathrm{mv}$.

The wave height/peak height of the polarogram was found to be proportional to the cystene concentration. The calibration curve was plotted by taking different known concentrations of cysteine in $0.02 \mathrm{M} \mathrm{NaCl}$ under identical experimental conditions as discussed above and recording the polarograms and plotting diffusion current (Id) versus cysteine concentration (Figure 3). A linear calibration was obtained from $11.8 \times 10^{-6} \mathrm{M}$ to $87.5 \times 10^{-6} \mathrm{M}$ with correlation coefficient of 0.997 .

Polarograms of a fixed concentration of cysteine $(2 \mathrm{mM})$ and varying concentrations of crocin $(0.1$ to $2 \mathrm{mM})$ in $25 \mathrm{ml}$ cell were recorded under said experimental conditions. The observed polarograms revealed that the peak potential $\left(E_{P}\right)$ of cysteine shifted to more electronegative value and the diffusion current/peak current was shortened with increasing crocin concentration. Thus revealing crocin-cysteine complex (adduct) formation (Figure 4).

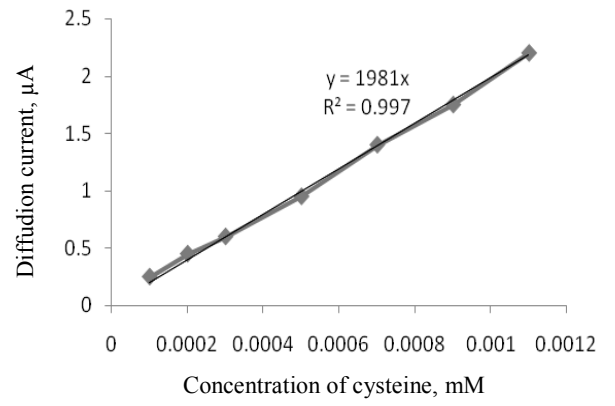

Figure (3). Calibration curve of cysteine hydrochloride at $\mathrm{pH} 5.2 \pm 0.01$.Other conditions as in Figure 2.

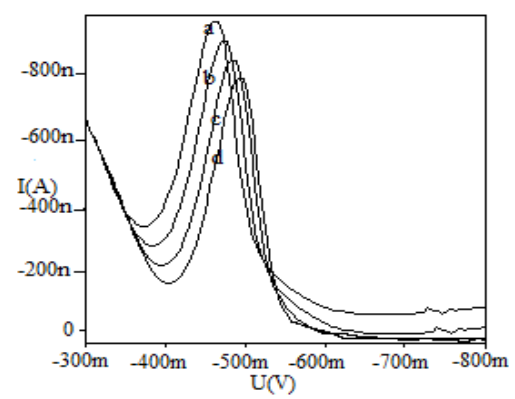

Figure 4. (a) Differential Pulse Polarogram of a fixed concentration of cysteine (2 $\mathrm{mM}) .(\mathrm{b}):$ (a) $+0.1 \mathrm{mM}$ of crocin (c): (b) $+0.1 \mathrm{mM}$ of crocin (d): (c) $+0.1 \mathrm{mM}$ of crocin in $0.02 \mathrm{M} \mathrm{NaCl}, \mathrm{pH} 5.2 \pm 0.01$, scan rate $20 \mathrm{mV} / \mathrm{s}$, pulse amplitude $50 \mathrm{mv}$. 


\section{Amperometric Titration of Crocin with Cysteine}

Keeping in mind the principle of amperometry, that for the amperometric titration at least one of the substances under study should be electroactive. Cysteine a polarographically active species has been chosen as an active species for the study of its interaction with crocin (polarographically inactive).

For amperometric titration of cysteine with crocin, experimental set containing $2 \mathrm{~mL}$ of $10^{-3} \mathrm{M}$ cysteine hydrochloride and $5 \mathrm{~mL}$ of $0.1 \mathrm{M} \mathrm{NaCl}$ as supporting electrolyte were taken in a polarographic cell. The total volume of the solution was made upto $25 \mathrm{~mL}$ with distilled water. The $\mathrm{pH}$ of test solution was adjusted to the desired value of $5.2 \pm 0.01$ using dil. $\mathrm{HCl} / \mathrm{NaOH}$ solutions. The plateau potential of the polarographic wave i,e cysteine $(-0.6 \mathrm{~V})$ was fixed on the potentiometer and current was read on the polyflex galvanometer.

Amperometric titration was then performed by gradually adding definite aliquots of the titrant $\left(10^{-3} \mathrm{M}\right.$ crocin $)$ of the same $\mathrm{pH}$ as that of titrate, the current changes were recorded on the galvanometer with each addition. The current so obtained after volume correction i,e $\mathrm{i}(\mathrm{V}+\mathrm{v} / \mathrm{V})$ was plotted against the volume of titrant added. The resulting current-volume plot was L shaped curve, (Figure 5a). The end point of titration was determined by the point of intersection of lines. The experiment was repeated in which crocin $\left(1 \mathrm{~mL} 10^{-3} \mathrm{M}\right)$ was taken in the polarographic cell as titrate and cysteine $\left(10^{-3} \mathrm{M}\right)$ as titrant under aforesaid experimental conditions. The $\mathrm{i}(\mathrm{V}+\mathrm{v} / \mathrm{V}) v s$. titrant volume plot resulted in $\lrcorner$ shaped curve. (Figure 5b). The end point indicated crocin: cysteine ratio of 1:2.

\section{Amperometric Determination of Crocin in Saffron Stigmas (Crocus Sativus)}

$10 \mathrm{mg}$ of the extracted crocin was dissolved in distilled water and the solution was made up to $100 \mathrm{~mL}$. This solution containing crocin was used in ampermetric titration. For amperometric titration of crocin with cysteine, experimental set was prepared by taking $1 \mathrm{~mL} 10^{-3} \mathrm{M}$ cysteine and $5 \mathrm{~mL}$ of $0.1 \mathrm{M} \mathrm{NaCl}$ as supporting electrolyte in a polarographic cell and the total volume was made upto $25 \mathrm{~mL}$ with distilled water. The $\mathrm{pH}$ of the solution was adjusted to $5.2 \pm 0.01$. A potential of $(-0.6 \mathrm{v})$ was applied on the potentiometer and the galvanometer reading was noted. The amperometric titration was then performed by gradually adding definite aliquots of solution of saffron extract containing crocin $(\mathrm{pH}=5.2)$ as titrant. The current changes were read on the galvanometer after each addition. The current so obtained after volume correction $\mathrm{i}(\mathrm{V}+\mathrm{v} / \mathrm{V})$ was plotted against volume of titrant added. The end point of titration was determined by the point of intersection of lines (Figure 5c).
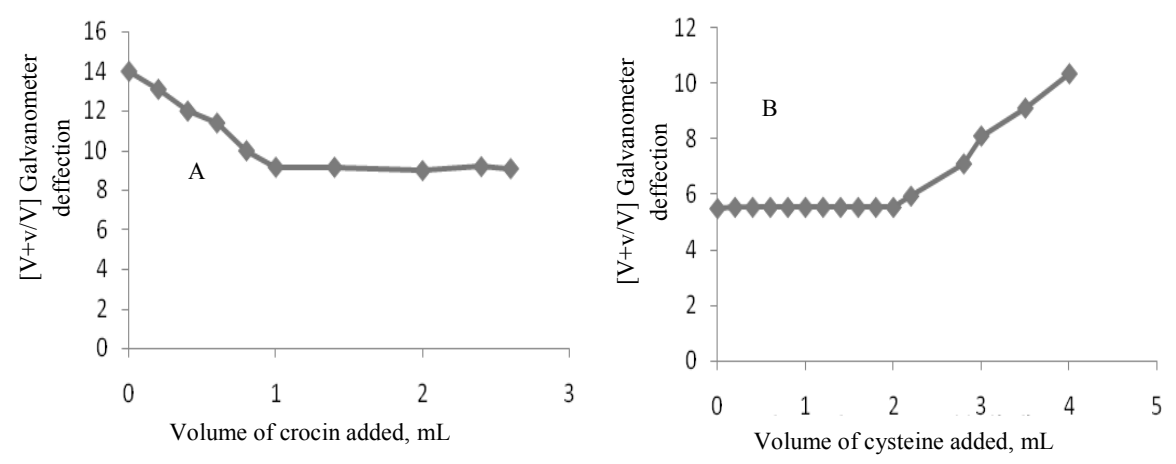


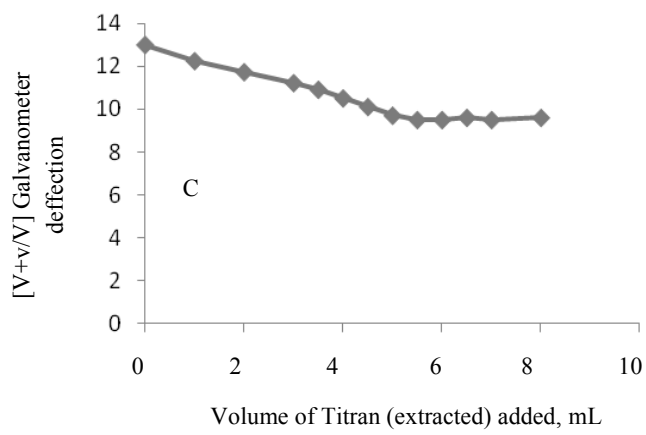

Figure 5. (A).Amperometric titration of Cysteine $(2 \mu \mathrm{M})$ with Crocin $(1 \mu \mathrm{M})$ in $0.1 \mathrm{M}$ $\mathrm{NaCl}, \mathrm{pH} 5.2 \pm 0.01$ (B). Amperometric titration of crocin $(1 \mu \mathrm{M})$ with cysteine $(1 \mu \mathrm{M})$ in $0.1 \mathrm{M}$ $\mathrm{NaCl}, \mathrm{pH} 5.2 \pm 0.01$.(C). Amperometric titration of cysteine $(1 \mu \mathrm{M})$ with saffron extract soluteon containing crocin in $0.1 \mathrm{M} \mathrm{NaCl}, \mathrm{pH}=5.2 \pm 0.01$.

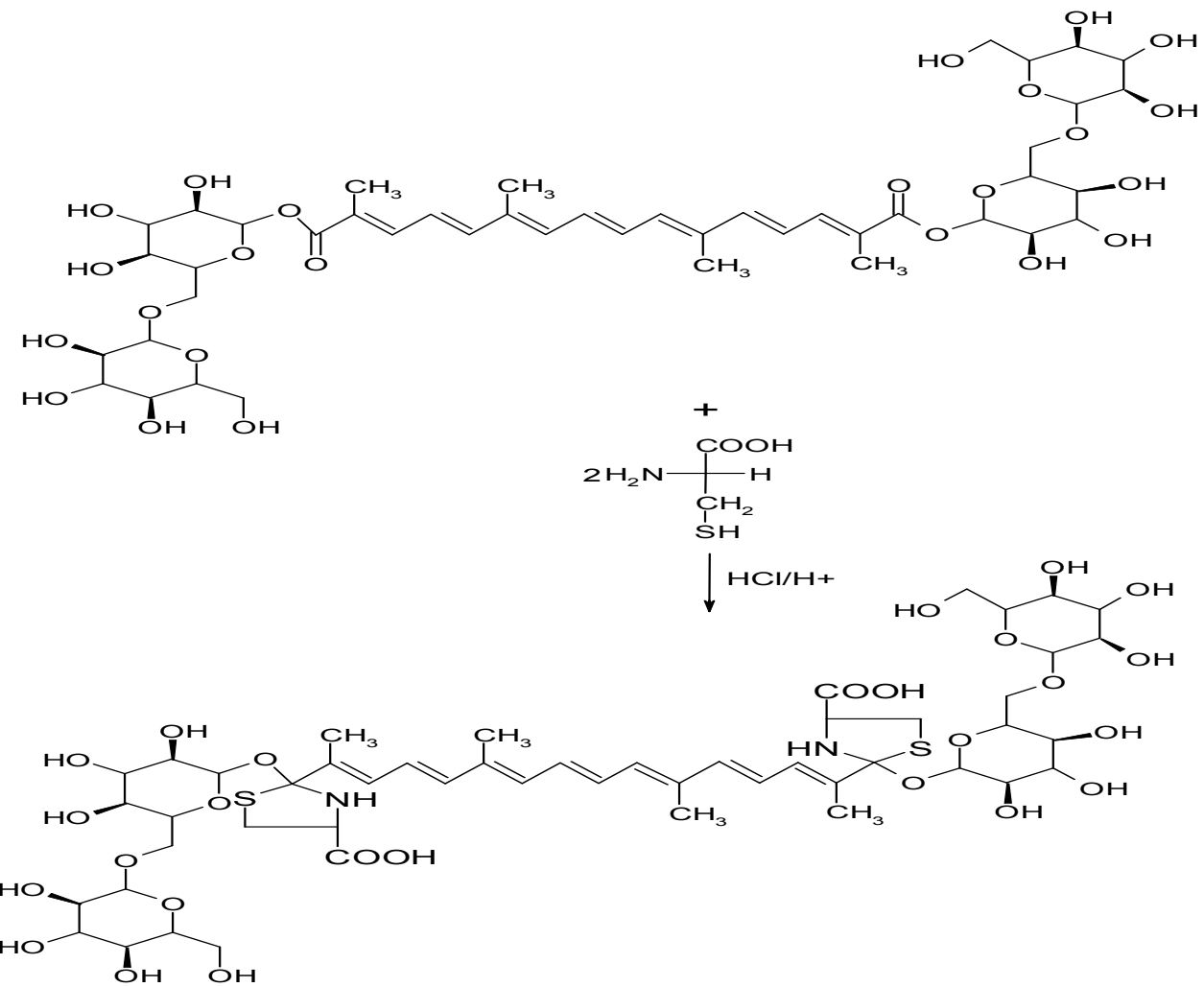

Figure 6. Reaction of crocin with cysteine.

\section{Results and Discussion}

UV-visible spectrophotometry showed that each crystallized crocin, saffron stigma extract and Fluka crocin represent the similar spectrum with two absorption peaks at $255 \mathrm{~nm}$ and $442 \mathrm{~nm}$.Further, the UV absorbance of crystallized crocin is more than Fluka crocin sample which indicates that crystallized crocin is more pure than Fluka Crocin Figure 7. 


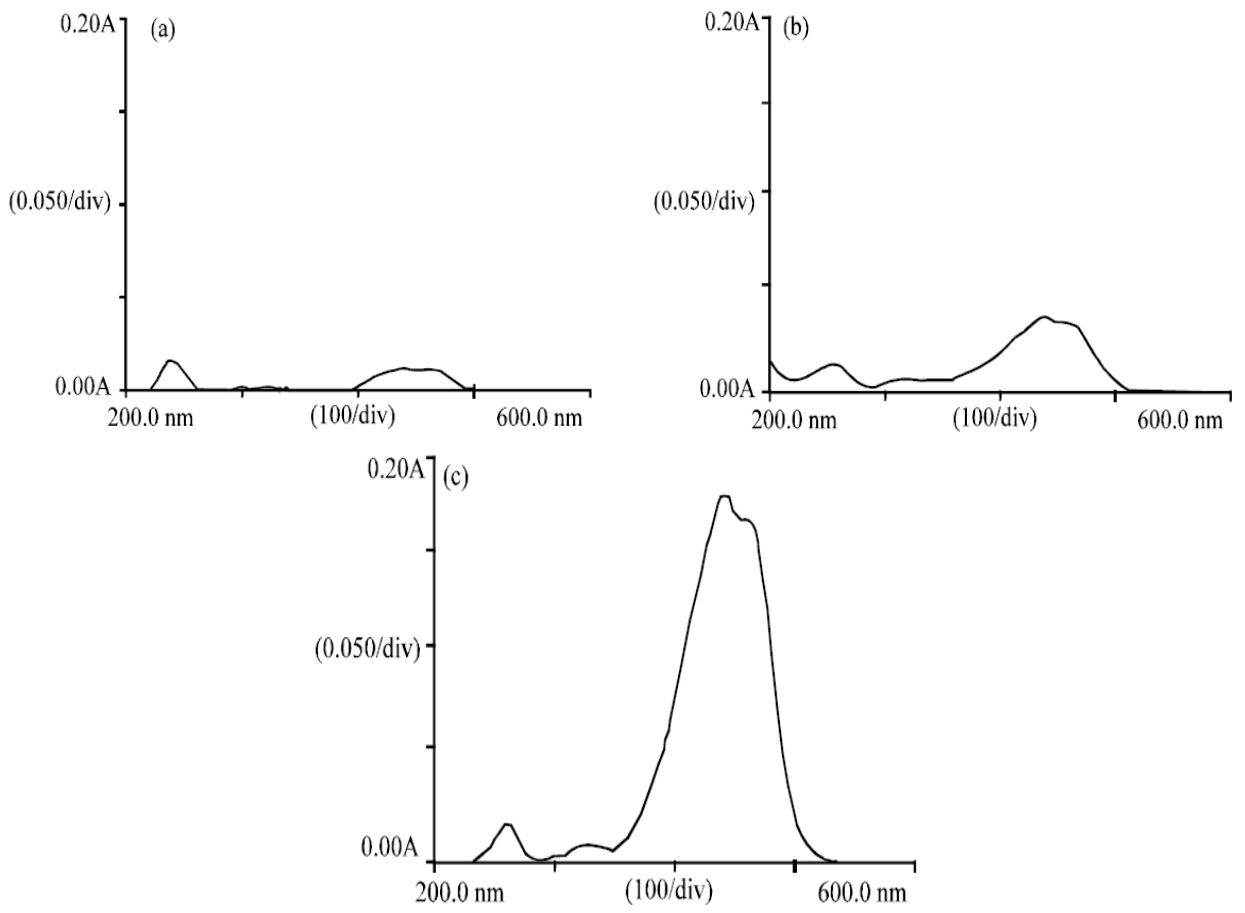

Figure 7. Spectrophotometry of samples in water $\left(2 \mu \mathrm{gmL}^{-1}\right)$, (a) Fluka crocin, (b) saffron stigma extract sample and (c) crystallized crocin.

Polarographic analysis showed that crocin is polarographically inactive. However, cysteine in $0.02 \mathrm{M} \mathrm{NaCl}$ at $\mathrm{pH}=5.2 \pm 0.01$ produces a well defined wave/peak with $\mathrm{E}_{1 / 2} / \mathrm{Ep}=$ $0.47 /-0.45 \mathrm{v}$ vs. SCE. The diffusion current and peak height of cysteine was found to be proportional to its concentration. On recording the polarograms of a set of solution containing a fixed concentration of cysteine and varying concentrations of crocin under aforesaid experimental conditions a gradual decrease in peak height/diffusion current was observed. Thus, indicating cysteine-crocin interaction. On performing amperometric titration between crocin and cysteine, the end point indicated a crocin to cysteine ratio of 1:2.The above amperometric titration procedure was used to determine the concentration of crocin in a sample of saffron. The concentration of crocin in saffron was found to be $2.13 \%$. This is in good agreement with the HPLC analysis as determined by earlier workers ${ }^{11-13,16}$. The purity of isolated crocin was found to be $96.81 \%$.Some experiments were carried out on recovery and the percentage recovery varied from 98.56 to $100.31 \%$. The relative standard deviation was found to be $2.17 \%$.

The results of FTIR spectra of crocin showed the following structurally important signals at $895 \mathrm{~cm}^{-1}$ (-CH=CH-trans), $1020-1100 \mathrm{c} \mathrm{m}^{-1}$ (C-O-C,ether), $1278 \mathrm{~cm}^{-1}$ (-C-O-,ester), $1580-1650 \mathrm{~cm}^{-1}$, (-C=C-, conjugated polyene), $1697 \mathrm{~cm}^{-1}\left(-\mathrm{C}=\mathrm{O}\right.$ str.ester), $2922 \mathrm{~cm}^{-1}$ (-C-H,str.aliphatic), and 3262$3441 \mathrm{~cm}^{-1}$ (-O-H str.). The IR spectrum of modified crocin with cysteine showed that carboxylic acid group of cysteine is retained giving a band at $1725 \mathrm{~cm}^{-1}$ due to carbonyl stretching of $-\mathrm{COOH}$ group and a band at $1250 \mathrm{~cm}^{-1}$ which is due to $-\mathrm{C}-\mathrm{OH}$ stretching. The band at $1697 \mathrm{~cm}^{-1}$ observed in the spectrum of crocin is absent in that observed for modified crocin indicating the involvement of carbonyl group of crocin in adduct formation resulting in the shifting of band due to conjugated 
polyene to $1581 \mathrm{~cm}^{-1}$. This indicate that cysteine reacts with crocin at its carbonyl group and a condensation product is obtained which contains a thiazolidine ring of the modified adduct. This is also supported by the reaction of cysteine with other carbonyl compounds like acetone ${ }^{18}$.

\section{Conclusion}

The validation of the proposed procedure for the quantitative assay of crocin was examined via an evaluation of the repeatability, recovery, selectivity and relative standard deviation. The method is useful for the quality control assay of the drug in pharmaceuticals and in fluids like serum, urine and blood. The developed method is superior over HPLC being cheap, easy and selective.

\section{Acknowledgment}

The authors are thankful to the Head, department of chemistry, Dr.Hari Singh Gour University Sagar (M.P) India, for providing necessary laboratory facilities and the University Grants Commission New-Delhi for financial support under its special assistance programme.

\section{References}

1 Chang P Y, Wang C K, Liang C T, and Kuo W, Yao Hsueh Hsueh Pao,1994, 11, 90-100.

2 Abdullaev F I, Toxicology In Vitro, 2003, 17(5-6), 751.

3 Ochiai T, Biochim Biophys Act., 2006, 1770(4), 578-584.

4 Yang Chem, Hao zhang and Tian Xi, Food Chemistry, 2008, 109, 484-492.

5 Abdullaev F I and Frenkel G D, Biofactors, 1992, 4, 43-45.

6 Abdullaev F I and Frenkel G D, Biofactors, 1992, 3, 201-205.

7 Escribano J, Alonso G L, Coca-prados M and Fernandez J A, Cancer Lett., 1996, 100(1-2), 23-30.

8 AbdullaevI F, Experimental Biology Med., 2002, 227, 20-25.

9 Hossein Hosseinzadeh, Hamid R, Sadeghnia, Toktam Ziaee and Aghdas Danaee, J Pharm Pharmaceut Sci (www.spscanada.org), 2005, 8(3), 387-389.

10 Hosseinzeteh H and Talebzadeh F, Kiecolt-Glaser and Glaser. Arch Irn Med., 2002, 5, 44-47.

11 Hadizadeh F, Mahdari M, Emami S A, Khashayarmanesh Z, Hassanzadeh M J and Asili, Acta Hort., 2007, 739.

12 Hadizadeh F, Mohajeri S A and Seifi M, Pak J Biol Sci., 2010, 13(14), 691-698.

13 Yeon Sil Park, Heung-Jin Choi and Seok Hun Yun, J Ind Eng Chem., 2001, 7(6), 375-379.

14 Zuman P, Polarography in medicine, biochemistry and pharmacy: Inter science publishers, 1958, 779 .

15 Meites L, Polarographic techniques, Inter science Publishers, Inc, New yark, $2^{\text {nd }}$ Ed., 1963 , pp. 693.

16 Hadizadeh F, Mohajeri S A and Seifi M, Pak J Biol Sci., 2010, 13(14), 691-698.

17 Angela C, Andrea S and Claddiu T, Env Health Perspectives, 2002, 110(5), 801- 805.

18 Gladys E W and Schroeder E F, J Biol Chem.,1928, 84, 296. 


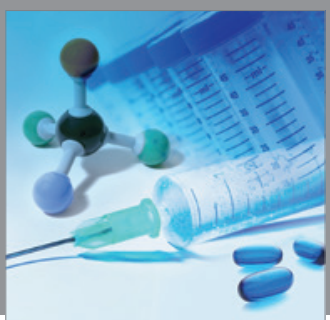

International Journal of

Medicinal Chemistry

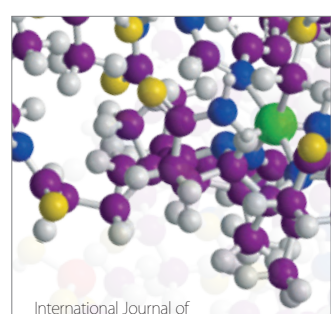

Carbohydrate Chemistry

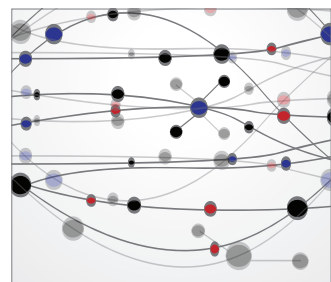

The Scientific World Journal
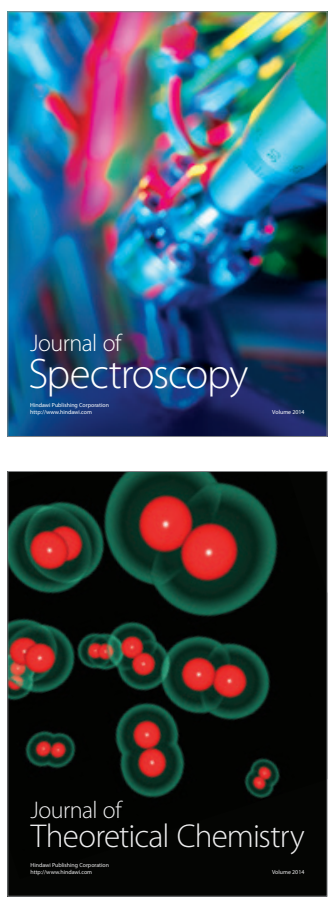
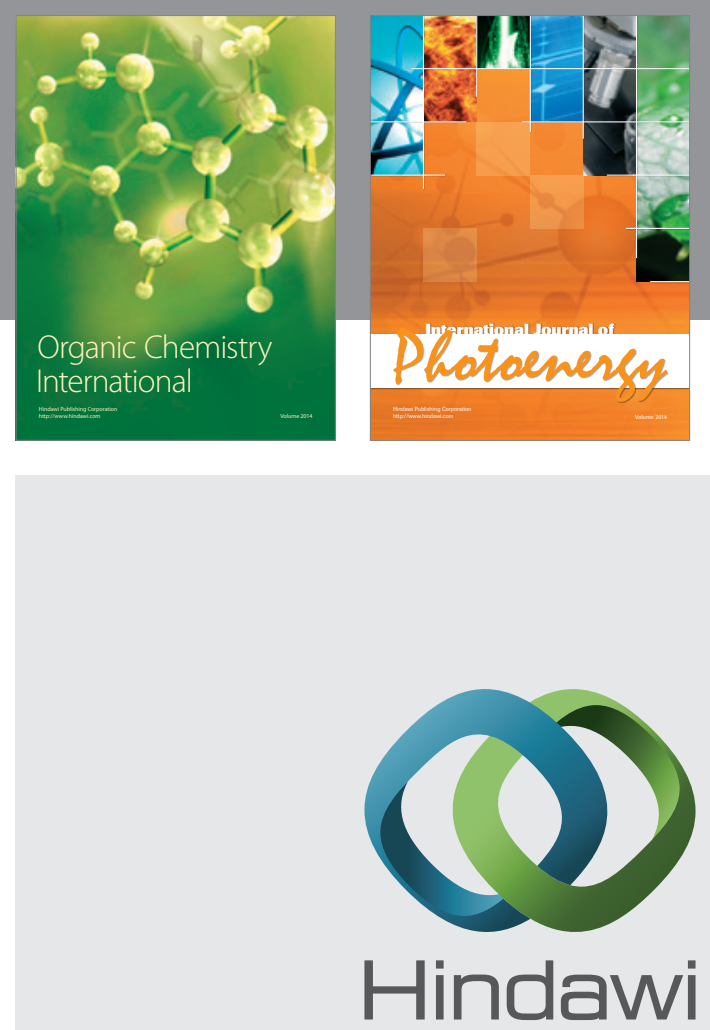

Submit your manuscripts at

http://www.hindawi.com
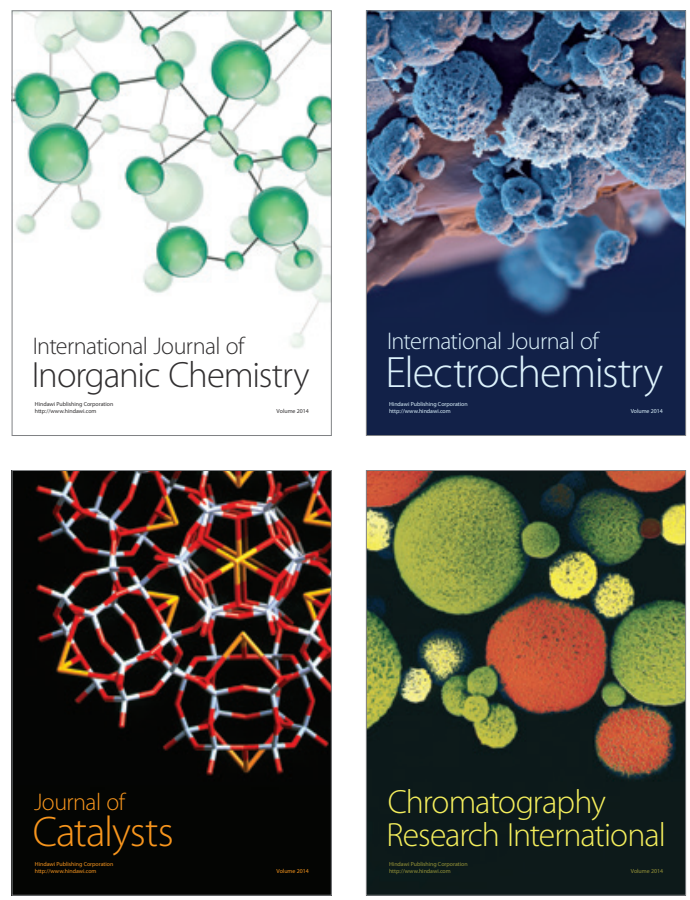
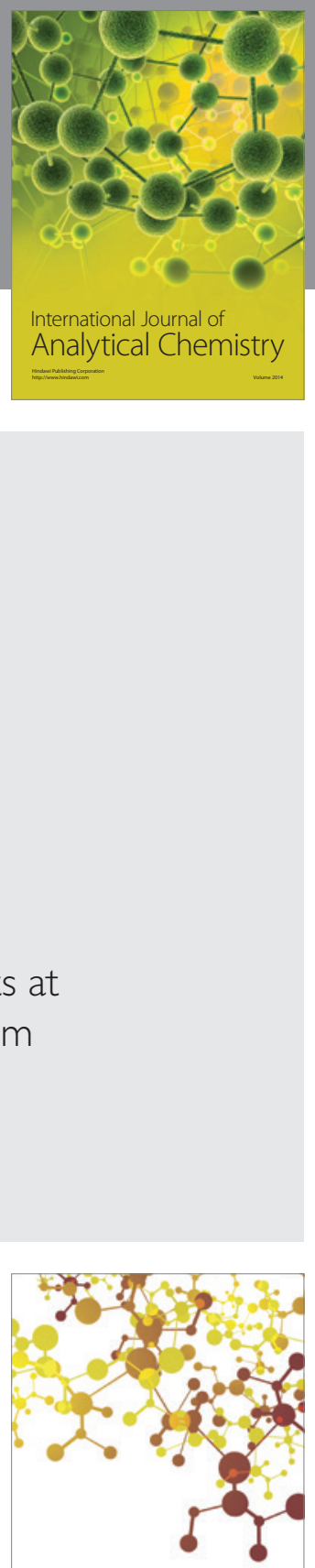

Journal of

Applied Chemistry
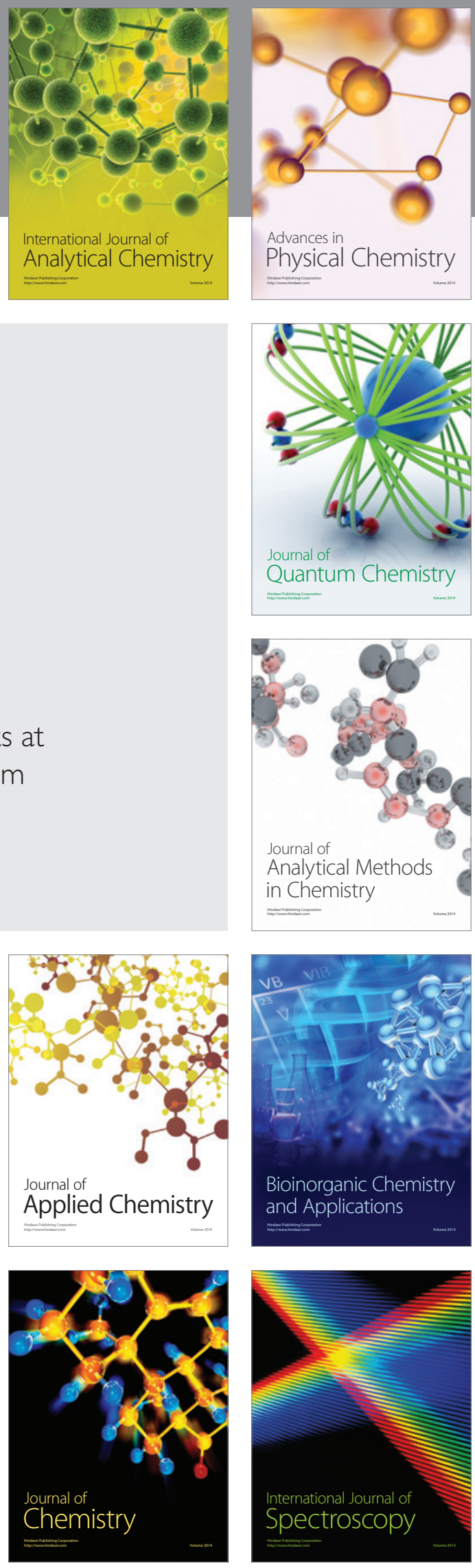